\title{
Música, Indústria Cultural e a regressão da audição: Contribuições da Teoria Crítica à emancipação humana ${ }^{1}$
}

\author{
Music, Cultural Industry and the regression of hearing: Contributions of Critical Theory to human \\ emancipation
}

La música, la Industria Cultural y la regresión auditiva: Aportaciones de la Teoría Crítica a la emancipación humana

Recebido: 22/03/2021 | Revisado: 28/03/2021 | Aceito: 04/04/2021 | Publicado: 14/04/2021

\begin{abstract}
Resumo
Atualmente a música está presente em quase todos os espaços sociais, mas isso não significa que contribua para aumentar a qualidade da formação do pensamento e do sentimento estético das pessoas. Elas servem sim, para entreter e para passar o tempo, mas dificilmente promovem a fruição. Diante do exposto, este estudo tem por objetivo examinar como a música foi utilizada pela indústria cultural para formatar a audição dos homens, contribuindo para a regressão da audição. É uma pesquisa qualitativa e o método utilizado é o crítico-dialético de natureza teórica, fundamentada em fontes bibliográficas que embasam a discussão dos conceitos. Em um primeiro momento discorre sobre o gosto musical que está muitas vezes condicionado pelas relações de produção, ressaltando como a música assim como as demais linguagens artísticas - foi sendo cooptada pela razão instrumental. Na sequência demonstra como a música em escala indústria tem contribuído para formatar a audição dos indivíduos, que estão acostumados com os mesmos acordes musicais, sem variação de timbres, apontando a negatividade desta situação, pois a mesma também pode contribuir para a formação estética. Conclui-se que uma música que existe uma distância entre um sucesso musical e sua qualidade estética. Filosoficamente a música possui uma potencialidade negativa que possibilita não apenas ser ouvida em momentos de lazer, mas também pode oportunizar uma experiência estética, resultando em um ato formativo.
\end{abstract}

Palavras-chave: Teoria crítica; Indústria cultural; Música de consumo; Regressão da audição.

\begin{abstract}
Currently, music is present in almost all social spaces, but this does not mean that it contributes to increase the quality of thought formation and aesthetic feeling of people. Music is used to entertain and to pass the time, but it hardly promotes fruition. In light of the above, this study aims to examine how music has been used by the cultural industry to format men's hearing, contributing to the regression of hearing. It is a qualitative research and the method used is the critical-dialectical of theoretical nature, based on bibliographic sources that support the discussion of the concepts. First, it discusses musical taste, which is often conditioned by production relations, emphasizing how music - as well as other artistic languages - has been co-opted by instrumental reasoning. In sequence, it shows how music on an industrial scale has contributed to format the hearing of individuals, who are used to the same musical chords, with no variation of timbers, pointing out the negativity of this situation, because it can also contribute to the aesthetic formation. It is concluded that there is a distance between musical success and its aesthetic quality. Philosophically, music has a negative potentiality that makes it possible not only to be heard in moments of leisure, but it can also provide an aesthetic experience, resulting in a formative act.
\end{abstract}

Keywords: Critical theory; Cultural industry; Consumer music; Regression of hearing.

\section{Resumen}

Actualmente, la música está presente en casi todos los espacios sociales, pero esto no significa que contribuya a aumentar la calidad de la formación del pensamiento y el sentimiento estético de las personas. Sirven para entretener y pasar el tiempo, pero difícilmente promueven la fruición. Teniendo en cuenta lo anterior, este estudio pretende examinar cómo la industria cultural utilizó la música para formatear el oído del hombre, contribuyendo a la regresión

${ }^{1}$ Este texto é parte da Tese da autora. 
de la audición. Se trata de una investigación cualitativa y el método utilizado es el crítico-dialéctico de carácter teórico, basado en fuentes bibliográficas que apoyan la discusión de conceptos. En un primer momento discute el gusto musical que suele estar condicionado por las relaciones de producción, destacando cómo la música -al igual que otros lenguajes artísticos- estaba siendo cooptada por la razón instrumental. A continuación, se demuestra cómo la música a escala industrial ha contribuido a formatear el oído de los individuos, acostumbrados a los mismos acordes musicales, sin variación de timbres, señalando la negatividad de esta situación, porque también puede contribuir a la formación estética. Se concluye que una música que hay una distancia entre un éxito musical y su calidad estética. Filosóficamente la música posee una potencialidad negativa que hace posible no sólo ser escuchada en momentos de ocio, sino que también puede oportunizar una experiencia estética, resultando en un acto formativo.

Palabras clave: Teoría crítica; Industria cultural; Música de consumo; Regresión auditiva.

\section{Introdução}

A música é uma das expressões artísticas mais utilizadas pelos homens! Adentra vários espaços sociais, inclusive a escola, que não está isolada do contexto histórico e social do qual está inserida. Adorno (1991), por sua vez, ao discorrer sobre a música na sociedade atual, alertava que: mais do que em qualquer outra época, os indivíduos tendem a obedecer a moda musical. Basta a mídia tocar alguma música várias vezes, que as pessoas assimilam a melodia e a canção vira sucesso. Geralmente, este tipo de música é conhecido por todos e é feita nos moldes industriais, pensada no ritmo que os ouvidos da população estão acostumados, para que logo se identifiquem com ela. Esse comportamento - centrado no consumo - tornou-se algo natural para quem se vê cercado de mercadorias padronizadas, inclusive os sons.

Diante do exposto, este estudo tem por objetivo examinar como a música foi utilizada pela indústria cultural para formatar a audição dos homens, contribuindo para a regressão da audição. É uma pesquisa qualitativa e o método utilizado é o crítico-dialético de natureza teórica, fundamentada em fontes bibliográficas que embasam a discussão dos conceitos. Em um primeiro momento discorre sobre o gosto musical que está muitas vezes condicionado pelas relações de produção, ressaltando como a música - assim como as demais linguagens artísticas - foi sendo cooptada pela razão instrumental.

Na sequência demonstra como a música em escala indústria tem contribuído para formatar a audição dos indivíduos, que estão acostumados com os mesmos acordes musicais, sem variação de timbres, apontando a negatividade desta situação, pois a mesma também pode contribuir para a formação estética. Conclui-se que uma música que existe uma distância entre um sucesso musical e sua qualidade estética. Filosoficamente a música possui uma potencialidade negativa que possibilita não apenas ser ouvida em momentos de lazer, mas também pode oportunizar uma experiência estética, resultando em um ato formativo.

\section{Metodologia}

Este estudo é uma pesquisa qualitativa de caráter teórico, com o referencial dos autores da Teoria Crítica que discutem a temática. Ao tomar como aporte teórico os autores da Teoria crítica realizou-se uma análise documental, que segundo Lüdke (1986, p. 38) "[...] pode se constituir numa técnica valiosa de abordagem de dados qualitativos, seja complementando as informações obtidas por outras técnicas, seja desvelando aspectos novos de um tema ou problema." O autor destaca que os documentos incluem leis e regulamentos, normas, pareceres, cartas, memorandos, diários pessoais, autobiografias, jornais, revistas, discursos, roteiros de programas de rádio e televisão até livros, estatísticas e arquivos escolares. A metodologia utilizada para realizar a análise documental é o materialismo dialético, que conforme Trivinõs (1987), busca explicar de forma lógica e racional os fenômenos objetos de pesquisas, sejam eles da natureza, da sociedade ou do pensamento. Sua concepção repousa na existência da evolução das ideias com base na interpretação dialética do mundo, de forma que a realidade científica seja construída ou enriquecida com a prática social e histórica do objeto do conhecimento. Ao utilizar a dialética para desenvolver o trabalho, esta pesquisa busca entender a materialidade por meio da reconstrução empírica e a reconstrução dos 
sentidos (por meio das relações sociais). O movimento dialético, contribui para transcender o sistema social, oportunizando ao homem libertar-se de sua existência e, ao mesmo tempo, denunciar a falsa aparência da sociedade de forma que muitos desses esmeram-se em expor um quadro referencial de análise em que tomam as categorias abstratamente.

\section{Resultados e Discussão}

Para compreender como aconteceu esse processo de regressão da audição na sociedade atual, é preciso examinar as condições materiais e históricas na qual esta situação se desenvolveu. Conforme Marcuse (1967), acredita-se que o pensamento humano parte de condições históricas e não pode ser isolado da camada física, real, em que o homem vive. Se a mediação entre pessoas e entre pessoas e objetos é imprescindível ao desenvolvimento do pensamento, e mais, se a qualidade e o alcance deste último, depende do conteúdo que permeia a linguagem, as interações, então, é preciso ter claro como tais condições se encontram hoje.

Em todos os seus gêneros, a arte está penetrada de momentos intelectivos. Basta dizer que as grandes formas musicais jamais se teriam constituído sem eles, sem a pré-audição, e a pós-audição, sem a expectativa e a lembrança, sem a síntese do dividido. Enquanto que tais funções se devem atribuir em certa medida à imediatidade sensível, portanto, que complexos parciais actuais suscitam as qualidades estruturais do passado e do futuro, as obras de arte, porém, atingem valores liminares onde semelhante imediatidade acaba, onde elas devem ser 'pensadas', não numa reflexão que lhes é exterior, mas a partir delas próprias: à sua congênita complexão sensível cabe a mediação intelectiva que condiciona a sua percepção (Adorno, 1970, p. 108).

Segundo autores clássicos da Escola de Frankfurt, como Adorno e Horkheimer (1990) e Marcuse (1967), a formação multilateral do homem é anulada no decurso da sociedade capitalista. O individual é subsumido pelo social, ocorrendo uma padronização do pensamento, dos gostos, dos valores, dos sentimentos e dos desejos que se voltam para o consumo. Desta forma, os elementos estéticos que contribuíram para a formação do pensamento humano, agora também se entregam à lógica do capital. Arzua (2001, p. 176), na mesma linha de raciocínio dos autores frankfurtianos destaca que "[...] a sociedade repressiva e uniformizada já não pode participar de nenhuma experiência estética que não reafirme os mesmos grilhões sob os quais está organizada". Com certeza, a lógica que impera na sociedade do consumo, é a do sempre igual, padronizada, sendo que as experiências formativas estão quase extintas. Dificilmente os indivíduos conseguem desvencilhar-se desta situação de massificação e realizar abstrações mais complexas, principalmente porque os ouvidos também estão condicionados aos sons repetitivos, não lançando desafios ao pensamento.

Diante das demais artes tradicionais, a música é a mais condizente com esse propósito devido a algumas de suas propriedades, das quais dificilmente se pode abstrair. A diferença antropológica entre o ouvido e o olho decorre de seu respectivo papel histórico enquanto ideologia. O ouvido é passivo. O olho é coberto de pálpebra; é preciso abri-lo. O ouvido acha-se aberto; não tem de dirigir-se tão atentamente a estímulos, senão que precisa antes do mais, deles se proteger. A atividade do ouvido, sua atenção, cresceu provavelmente mais tarde, com a intensidade do Eu; no interior das tendências gerais de regressão, as qualidades tardias do Eu; se perderam num piscar de olhos (Adorno, 2011, p. 131).

Adorno (2011) explica a diferença entre o sentido da audição e da visão, e destaca que os sons e a linguagem que auxiliaram na formação do pensamento humano em sua história, atualmente, principalmente no que se refere à música, tem basicamente se restringido em clichês previamente fabricados, que por sua vez encerra conteúdo ideológico. "Desde a Revolução Industrial, a música inteira sofre com a não conciliação entre o universal e o particular" (Adorno, 2011, p. 158).

No que se refere à música, somente depois que a técnica musical e seu uso social se transformou em força produtiva, a socialização racional da produção cultural foi sendo padronizada em seu todo: a atividade composicional, o trabalho artístico, a 
técnica composicional, faculdade interpretativa de seus reprodutores e os modos de proceder da reprodução mecânica. Estas relações de produção compreendem as condições econômicas e ideológicas da Indústria Cultural que por sua vez determinam o que irá para as paradas de sucesso ou não.

Por conseguinte, Adorno (2011) destaca a importância de se entender como a sociedade aparece na música e como esta pode interferir na sociedade, pois o gosto musical está muitas vezes condicionado pelas relações de produção e as relações de produção determinam as forças produtivas. Mesmo assim, é interessante observar que a negatividade desta situação pode desencadear as forças produtivas para alterar as relações de produção - inclusive criá-la.

É importante entender este contexto, pois conforme Fabiano (2001), a cultura subsumida ao processo industrial, tem sua dimensão espiritual reduzida a uma dimensão integrativa e administrada. "A condição de lazer e distração acabam por desfigurar o sentido que a cultura sempre exerceu: civilizar e emancipar o homem dos limites da ignorância pelo aprimoramento da razão" (Fabiano, 2001, p. 136).

Adorno (1986b), escreve que a possibilidade de fruição e de experiência concentrada e consciente da arte só é possível para aqueles que escapam desta situação, pois para chegar no atual estágio, a produção musical - assim como as demais linguagens artísticas - foi sendo cooptada pela razão instrumental ${ }^{2}$. O processo de pensar mecânico determinado pela razão instrumental, contribuiu para naturalizar a alienação do homem em relação aos objetos, bem como a reificação do próprio espírito, ou seja, o indivíduo não se reconhece no processo de produção e se torna, ele mesmo, objeto do metabolismo do modo de produção capitalista (Moreira \& Silva, 2018). Segundo Adorno e Horkheimer (1985) o indivíduo precisa submeter-se ao trabalho alienante e consumir compulsivamente as mercadorias que estão para ele dispostas. E aqui, a mídia passa a exercer papel fundamental de manipulação do ser humano. O desenvolvimento científico e tecnológico que ocorreu no século XX, geraram uma mudança no modo de vida dos homens sem precedentes, especialmente no campo da linguagem e da imagem.

Dar-se bem equivale a ajustar-se ao aparato. Não há espaço para autonomia. A racionalidade individualista transformou-se em submissão eficiente à seqüência previamente dada de meios e fins. Esta absorve os efeitos libertadores do pensamento e as várias funções da razão convergem para a manutenção incondicional do aparato (Marcuse, 1997, p. 119).

Os indivíduos, ao viverem sob o estigma da racionalidade instrumental, acabam por perder sua própria individualidade. Todavia, não percebem a realidade como castradora, principalmente porque o aparato que produz esta sociedade elimina o pensamento diferente. Ao perpetuar o modo de produção, a razão perpetua sua própria alienação. Ela não consegue fugir aos padrões impostos como normais. Arzua (2001) destaca que no século XVII inicia a aproximação da linguagem musical com a linguagem falada, sofisticando-se com o tempo, tanto em relação aos pontos de contato, como naqueles pontos onde ocorre o afastamento - caracterizado pelas dissonâncias.

[...] as investidas dissonantes ganharam cada vez mais espaço no século XIX - importância de Beethoven. Ocorre a progressiva perda da hegemonia da forma tonal na composição. Essa mudança se verifica com maior força no final do século XIX e início do século XX e encontrará sua radicalização em Schoemberg, com sua criação da série dodecafônica (Arzua, 2001, p. 176).

2 No início da sociedade burguesa - séculos XVI e XVIII - os indivíduos ainda tinham algum controle sobre seu tempo e seu espaço. Mas, com o desenvolvimento industrial, perdem essa liberdade em prol da eficiência no trabalho com as máquinas. A modernidade livra o homem do pensamento místico, porém a razão instrumental ajusta-o à obediência e à servidão (Palangana, 1998). 
Para este autor, na mesma linha de raciocínio de Adorno (2007), o dodecafonismo ${ }^{3}$ não leva a música a lugar algum e não proporciona a fruição dos ouvintes, pois o feito musical se repete e por isso não tem nenhuma função, convertendo-se em um esforço inútil. A dificuldade do ouvinte encontra-se no fato de recusar o processo de reificação que sofre a cultura em um sentido estético generalizado. Este processo teve começou no final do século XIX.

\section{A Indústria Cultural e a padronização do gosto musical}

Conforme Duarte (2001), no início do século XX que a Indústria Cultural foi apropriando-se do caráter estético da música como mercadoria, relacionando a existência de um aparato sensorial, capaz de seduzir o ouvinte que foi tratado como um comprador potencial.

A indústria cultural é a integração deliberada, a partir do alto, de seus consumidores. Ela força a união dos domínios, separados há milênios, da arte superior e da arte inferior. Com prejuízo para ambos. A arte superior se vê frustrada de sua seriedade pela especulação sobre o efeito; a inferior perde, através de sua domesticação civilizadora, o elemento de natureza resistente e rude, que lhe era inerente enquanto o controle social não era total (Adorno, 1986a, p. 92-93).

Isto aconteceu quando os meios de comunicação de massa começaram a direcionar a atenção, a audição e o pensamento das pessoas apenas ao que lhe interessa, ou seja: o consumo. "Desse modo, não é enfatizado o que convém ao sistema, mas suprimido $[. .$.$] qualquer elemento que poderia conduzir seriamente a questionamentos acerca de sua natureza e$ pressupostos" (Duarte, 2001, p. 35).

Os indivíduos, ao viverem sob o estigma da racionalidade instrumental, acabam por perder sua própria individualidade. Fianco (2020) destaca que as dificuldades de expressão estética em um mundo dominado pela lógica do mercado, reflete a subserviência dos homens que durante anos foram moldados pelo pensamento dominante da burguesia. Desta forma, não percebem a realidade como castradora, principalmente porque o aparato que produz esta sociedade elimina o pensamento diferente. Ao perpetuar o modo de produção, a razão perpetua sua própria alienação. Ela não consegue fugir aos padrões impostos como normais. Diante da padronização e da fabricação da arte em grande escala. Paralelamente ocorre um trabalho de formatação dos gostos, sentimentos e desejos dos indivíduos, que se voltam cada vez mais para o consumo.

Em viva oposição à arte tradicional, a arte nova salienta o momento outrora oculto do fabricado, do produzido. A parte do que nele é [...] cresceu tanto que as tentativas para levar o processo de produção a perder-se na coisa estariam de antemão voltadas ao fracasso. Já a geração precedente tinha limitado a pura imanência das obras de arte, ao mesmo tempo que as impelia até ao extremo [...] É com razão que se constatou a convergência da obra de arte tecnicamente integral e totalmente fabricada com a obra absolutamente fortuita; sem dúvida o que aparentemente não parece fabricado é-o com maior razão (Adorno, 1970, p. 39).

$\mathrm{Na}$ sociedade industrial avançada, tem-se uma identificação imediata e automática do indivíduo com a sociedade e seus produtos. Duarte (2001) destaca que a dominação pelo estético no capitalismo ocorre em função de dois elementos: 1. existência de meios tecnológicos; 2. Utilização desses meios para produzir adesão àquilo que parece. "A arte não só entra no

3 O dodecafonismo utiliza, os doze graus da escala cromática, sem qualquer relação hierárquica entre eles, prescindindo das relações do sistema tonal. Os doze graus são apresentados em uma série de doze sons, dodecafônica, que constitui em um esquema formal básico que atua como princípio organizador do tema. Cada vez que a uma nota dada você acrescenta uma outra nota, você lança uma dúvida sobre o que queria dizer a primeira nota. Se, por exemplo, você faz seguir um Dó por um Sol, o ouvido pode se perguntar se você vai prosseguir em Dó Maior, ou em Sol Maior, ou mesmo em Fá Menor, em Mi Menor, etc., e a adição das notas seguintes ajudará ou não na solução desse problema. Você provocou assim uma impressão de incerteza, de desequilíbrio, que vai se acentuar com a sequência da peça e se encontrará reforçada por uma flutuação da mesma ordem, relativa ao ritmo. O método pelo qual você consegue restabelecer assim o equilíbrio comprometido é a meu ver a verdadeira 'ideia' de uma composição (Schoenberg, 1977 apud Loutreiro, 2016). 
circuito das mercadorias, mas serve de veículo ideológico ao poder social. Não pode ser de outra maneira nesta sociedade onde tudo deve ser pesado, medido, rotulado, vendido e consumido imediatamente" (Hartmann, 2001, p. 81).

O trabalho social, sem o qual não há vida, engendra o prazer do consumo. No entanto, o uso dos bens fabricados é um meio de o poder social manter a cadeia produtiva com o objetivo de lucro. Na esfera de consumo na qual a música está inserida, esta torna-se objeto social e mercadoria (Adorno, 2011). Ao verificar as consequências sociais da tecnologia moderna, percebe-se a pouca capacidade de reflexão, de entendimento da sociedade de que os homens dispõem, o que facilita sobremaneira a dominação.

A tecnificação da arte é provocada tanto pelo sujeito, pela consciência desiludida e pela desconfiança contra a magia enquanto véu, como pelo objecto, isto é, pela maneira como as obras se devem obrigatoriamente organizar. A possibilidade de semelhante organização tornou-se problemática com o declino dos processos técnicos tradicionais, que vigoraram até à época atual (Adorno, 1970, p. 75).

Até atingir as massas, a música está sujeita a uma sequência de fabricação pré-determinada, onde o controle preordenado oferece liberdade de escolha aos indivíduos com pouca escuta, ou pouco estímulo auditivo, pois este, o gosto do ouvinte, foi padronizado neste processo. Tal capacidade foi sendo minada no e por meio do processo de trabalho capitalista devido ao modo como essa atividade se realiza -, bem como por meio da cultura engendrada nessas mesmas relações. Trata-se, aqui, de questionar como a tecnologia é produzida e utilizada na sociedade moderna, e não o seu potencial em si. Neste contexto, a arte oferece a felicidade que a sociedade existente nega aos homens, é só uma promessa, da qual a realização está distante. Isso faz oscilar a arte entre utopia e realidade.

A razão instrumental influenciou a produção artística e hoje a Indústria Cultural ${ }^{4}$ em larga medida atua no psiquismo dos consumidores que são induzidos a gostar da música que lhe é oferecida pela mídia. Conforme Hartmann (2001), a arte está sujeita à lei da objetificação, ela não pode evitar uma espécie de fetichismo, pois, também, matam o que elas objetivam, arrancando-a do contexto e da vida real. O pensamento técnico infiltra-se na produção musical, que ao transformá-lo em objeto de dominação, elimina o próprio ser humano como sujeito dessa relação, coisificando-o também. A tecnologia, a serviço do mercado, disfarça as contradições sociais, desviando a atenção dos indivíduos, e se centra na aquisição, no consumo de supérfluos e não nas necessidades humanas fundamentais.

Adorno (1986a) afirma que, a dominação técnica é um engodo que tolhe a consciência das massas e impede a emancipação; quer dizer, impede os homens de se rebelarem contra o modo de ser estabelecido, de pensarem uma outra forma de organização, onde todo esse instrumental pudesse ser explorado na perspectiva da humanização.

Quando Adorno (1991) realizou sua análise sobre a Indústria Cultural, o rádio era essencial para o processo de padronização do gosto da população pelas músicas das paradas de sucesso. Com o intuito de tornar acessível a cultura superior e enfatizar a ideia de igualdade social, a Indústria Cultural facilitou a aquisição de obras de grandes clássicos da música e da literatura, reproduzindo-as em escala industrial. Atualmente a Indústria Cultural adentra os lares por meio da Internet, celulares e aplicativos como o spotfy $y^{5}$ que realizam a mesma função do rádio, mas de maneira muito mais abrangente e ampla. Ao serem popularizadas, essas obras perdem a dimensão formativa, o significado social e se tornam meros objetos comerciais, como outros quaisquer. Dessa forma, a cultura se reduz à comunicação esvaziada de sentido histórico. "Em nome dos consumidores,

4 Esta exploração comercial e cultural a que os indivíduos estão subjugados, Adorno e Horkheimer (1990) denominam de Indústria Cultu ral, para contraporse ao termo cultura de massa, como uma cultura surgindo das massas e formando a arte popular.

5 Spotify é um serviço de streaming de música, podcast e vídeo que foi lançado oficialmente em 7 de outubro de 2008 . É o serviço de streaming mais popular e usado do mundo. Ele é desenvolvido pela startup Spotify AB em Estocolmo, Suécia ( https://www.google.com.br/search?s ource=hp\&ei=SJZXd7AEvm55OUP0ry2uAw\&q=o+que+\%C3\% A9+spotify\&oq=o+qu $\quad$ e+\%C $\quad 3 \%$ A9+ $\quad$ tfy\&gs_l=psyab.1.0.0i1017j0i22i3013.845.4590..7588...0.0..0.171.1960.0j15..........1..gws-wiz.......0i 131j0j0i22i10i30.tlnEY h04 1JY). 
os que dispõem sobre a cultura reprimem e suprimem aquilo em que ela vai além, e só deixam sobrar aí o que preenche a sua finalidade indubitável" (Adorno, 1986a, p. 83). A imediaticidade das músicas oferecidas pela Indústria Cultural intensificam o lucro para alguns, e possibilitam a má consciência da população.

Como destaca Arzua (2001), a progressiva emancipação de elementos como a melodia, o ritmo, a harmonia, realizada pela música contemporânea, foi subjugada pela técnica.

A tecnificação, braço prolongado do sujeito dominador da natureza, aliena as obras de arte da sua linguagem imediata. A legalidade tecnológica recalca a contingência do simples indivíduo que reduz à obra de arte. O mesmo processo, com o qual enquanto morte da alma o tradicionalismo se escandaliza, traz à linguagem nos seus produtos mais elevados a obra de arte, em vez de a partir daí se declarar um elemento psicológico ou humano, como hoje com volubilidade se afirma (Adorno, 1970, p. 76).

Por meio da técnica o compositor domina os componentes da música, mas ao mesmo tempo, limita a criatividade do artista. Não podendo ser realidade, a obra revela, em sua negação a aparência de sua existência. Adorno (1970) postula que, a verdadeira autonomia da música consiste em não se reduzir à categoria de porta voz de coisa alguma, daí a inutilidade de lançar à estética musical uma tarefa que não pode cumprir, simplesmente porque não é sua tarefa.

Por este motivo, Adorno (2007) desenvolve reflexões sobre a música de consumo, destacando que o mercado se encarrega de formar gostos e o consumo de música com fins lucrativos. A queixa de Adorno sobre a decadência musical em 1938, ainda é atual quando se observa o grande campeão de vendas “Acordando o prédio”, de Luan Santana ${ }^{6}$.

É necessário refletir sobre a distância existente entre um sucesso musical e a sua qualidade estética. Conforme Adorno \& Horkheimer (1985, p. 114) “[...] eles não precisam mais se apresentar como arte”, pois a indústria do consumo busca cifras altas. Para garantir o lucro, suprimem qualquer dúvida quanto à necessidade social de seus produtos. Neste contexto surge uma característica deste século: a música - e outros bens de consumo - torna-se descartável, e o ouvinte torna-se mais uma peça na engrenagem.

Nogueira (2001) atenta para um problema: o gosto musical. Assim como Luria (1979, p. 73), afirma que o homem, por intermédio das relações sociais é que se torna um ser humano distinto de outros animais.

Desde o momento em que nasce, a criança forma o seu comportamento sob a influência das coisas que se formaram na história: senta-se à mesa, come com colher, bebe em xícara e mais tarde corta o pão com a faca. Ela assimila aquelas habilidades que foram criadas pela história social ao longo de milênios. [...] A grande maioria de conhecimentos, habilidades e procedimentos do comportamento de que dispõe o homem não são o resultado de sua experiência própria mas adquiridos pela assimilação da experiência histórico-social de gerações [...].

A apropriação dos elementos culturais, acontece por meio da mediação de adultos, ou de crianças, nas relações sociais, nas quais o indivíduo vai se apoderando da arte e de suas linguagens, como a música. Diante destas considerações, é preciso questionar, até que ponto pode-se entender o gosto por determinados estilos musicais, como uma opção pessoal e não como construção social? Adorno (1991), também escreve sobre o gostar do que se reconhece auditivamente. O que as pessoas apreciam hoje? Não seria o que escutam o dia todo no rádio, na novela, na internet, transportes coletivos, videoclipes, dentre outros?

Nesta perspectiva, Nogueira (2001) cita em seus estudos o exemplo da Sinfonia Primavera de Vivaldi. A autora percebeu que seus alunos conhecem e gostam desta obra, porque era tema de uma propaganda, ao contrário da Sinfonia Verão, que não era conhecida dos alunos pesquisados e não demonstram uma preferência musical por ela.

6 “Luan Santana (1991) é um cantor e compositor brasileiro de música romântica, pop e sertaneja. Entre seus sucessos estão: Meteoro, 'Cê Topa', Tanto Faz, Tudo Que Você Quiser e Escreve Ai." ( https://www.ebiografia.com/luan_santana/). 
Outro exemplo que a autora cita é a peça Carmina $B_{u r a n a}{ }^{7}$, por fazer parte de uma trilha sonora, foi uma das peças mais procuradas em lojas, tocada em formaturas e solenidades. Percebe-se com este exemplo a lógica que perpassa as paradas de sucesso de uma determinada canção, que normalmente está ligada à sua estratégia de divulgação. Neste sentido, o gosto musical está sendo moldado, sendo necessário um olhar cauteloso sobre o papel preponderante que as mídias desempenham na "escolha musical da população" (Nogueira, 2001, p. 189).

Estes exemplos confirmam as ideias de Penna (2012), que percebe que a sensibilidade e o gosto por determinado estilo musical, refere-se a uma sensibilidade adquirida em um processo e internalização dos ritmos e estilos que mais se escutam durante a vida das pessoas.

A cultura mercantil não surge das massas. Imposta de cima e com fins consumistas, é uma cultura que massifica, espalhando valores, regras de conduta, padrões de pensamento uniformizados. A arte inferior e a superior, do ponto de vista formativo, tornam-se uma só. A segunda perde os elementos de resistência que possuía e, ao invés de propiciar a emancipação, agora gera dependência e regressão.

Fabiano (2001) escreve que a reflexão em um universo tão limitado, reverte-se em conformismo. Evidentemente, podem ser encontrados filmes, músicas, obras de arte que formam no sentido omnilateral ${ }^{8}$, porém essa não é a situação dominante. $\mathrm{O}$ consumidor tem sempre a impressão de estar ganhando, quando quem lucra são os produtores, as grandes indústrias que financiam os programas, as gravações, dentre outros.

É claro que a abolição do privilégio cultural por liquidação e venda a preços módicos, deixou mais democrática a produção artística para a maioria da população, mas há que se questionar se não contribui também para tornar as condições sociais atuais, à própria ruína da cultura? Segundo Adorno (1991) a música de consumo atualmente ao invés de elevar o sentimento, o gosto estético, parece contribuir ainda mais para o emudecimento dos homens, para a morte da linguagem como expressão, para a incapacidade de comunicação.

Na sociedade industrial, a música é feita para preencher o silêncio que se instala entre as pessoas. Quando chegam do trabalho, os indivíduos são tomados pelo cansaço e logo ligam o rádio ou a TV para se distraírem. As pessoas tendem a se afastar - estando na mesma casa - e os momentos de diálogo são cada vez menores. Por outro lado, o tempo que passam assistindo a TV ou ouvindo o rádio aumentou sensivelmente. O consumo e o caráter fetichista dos bens culturais devem ser entendidos na forma de organização social que os origina. A sociedade mercantil manipula e oculta os mecanismos de exploração e alienação de maneira tal que os indivíduos perpetuam e legitimam essa estrutura de produção, reprodução e consumo.

A Indústria Cultural não apenas se encarrega de configurar os desejos dos indivíduos, como difunde valores éticos e estéticos, gerando uma falsa experiência social nos homens à medida que não permite que os mesmos decidam, conscientemente, sobre seus desejos, valores, gostos, enfim sobre sua vida. Kiihl (2019) pautada na Teoria Crítica indica que os homens precisam conhecer a história das conquistas dos homens por meio do trabalho e da vida em sociedade para que assim possam se contrapor ao processo de semiformação que impera na sociedade capitalista. Para tanto é preciso que a educação emancipe os homens. O próximo item irá discorrer sobre esta questão.

\footnotetext{
7 Sem dúvida um dos maiores hits da música clássica, Carmina Burana é de longe a obra mais conhecida do compositor alemão Carl Orff (1895-1982). Ela foi escrita em 1935 e estreada em junho de 1937 em Frankfurt. Obra que a princípio não agradou muito aos líderes nazistas mais à frente foi glorificada por eles, e sua estreia em Milão em 1942 foi saudada como uma gloriosa junção cultural dos dois países fascistas. Vale a pena lembrar que esta obra é a única produção artística da Alemanha nazista a permanecer conhecida sendo que nem os pintores, nem os compositores e nem os escritores que escreveram seguindo as regras do partido são hoje lembrados. Orff fez uma seleção dentre os mais de 300 textos escritos na idade média encontrados num mosteiro da Baviera. O nome Carmina Burana significa em latim Canções do mosteiro Benediktbeuern. Orff escolheu apenas 22 poemas e os agrupou em assunto para construir um tipo de enredo (Colarusso, 2013).

8 O modelo omnilateral de educação, segundo o pensamento marxista, devolve ao homem a possibilidade de revolucionar sua postura e o seu pensamento diante do sistema capitalista, podendo, desse modo, modificar o quadro de desigualdades inerentes à sociedade capitalista. Refere-se a uma formação humana oposta à formação unilateral provocada pelo trabalho alienado, pela divisão social do trabalho (Ribeiro; Sobral; Jataí, 2016).
} 


\section{A Música, a regressão da audição e a experiência estética}

No contexto da sociedade do consumo, a introdução dos meios eletrônicos na vida diária do homem causa impactos que influenciam diretamente a maneira de perceber e compreender a realidade. As tecnologias de comunicação fazem parte da sociedade industrial, são gestadas e produzidas em função das necessidades do capital. Assim sendo, não podem ser tomadas independentemente dos interesses que se situam na base dessas produções. Tampouco pode-se ignorar a lógica que permeia esses recursos e que limita o uso dos mesmos a uma única dimensão.

As tecnologias de comunicação, ou mass media, desenvolvidas no início do século XX, têm como característica fundamental a comunicação de massa. Produzidos sob o modelo industrial, tais recursos visam promover o comércio. Não obstante, "[...] a comunicação de massa, com seu ruído orquestrado, incentiva a permanência do estado de coisificação" (Palangana, 1998, p. 168).

O consumidor não percebe que pode experimentar a música como algo em si, que possibilite não apenas um momento de lazer, mas sim que pode possibilitar a experiência estética e um ato formativo. Isto porque a música também está padronizada e formatada nos padrões do consumo. Em o "O fetichismo da música e a regressão da audição", Adorno (1991) demonstra como a cultura foi apropriada deste caráter fetichista, que por sua vez se torna hegemônico diante da produção cultural. A arte ficou presa à rotina do sempre igual, repetitivo, cansativo, seguindo normas "[...] no sentido da repetição de modelos pré-fabricados" (Adorno, 1991, p. 103). A compreensão dos enredos de grandes obras que são transcritos para a televisão e para o cinema ou de sinfonias musicais não requer esforço algum. O enquadramento das histórias e o tom artificial das gravações - sempre perfeitas e lineares - fazem desaparecer os espaços de tensão e os traços de protesto presentes no original.

Adorno (1991) já alertava, naquele momento histórico99, mais do que em qualquer outra época, que todos tendiam a obedecer a moda musical. Atualmente as pessoas em geral não conseguem ter uma opinião própria, e nem decidir com liberdade quanto ao que lhe é apresentado, já que tudo o que lhe é oferecido é tão idêntico que a preferência quanto a esta ou aquela música, se refere apenas à situação concreta em que a mesma é ouvida.

Se objeta que a música ligeira e toda a música destinada ao consumo nunca foram experimentadas e apreciadas segundo as mencionadas categorias, não há como negar a verdade desta objeção, esta espécie de música é afetada pela mudança porque proporciona entretenimento, atrativo e prazer, porém, apenas para ao mesmo tempo recusar os valores que concede (Adorno, 1991, p. 80).

A massificação da música, na concepção de Adorno (1991), leva à degeneração humana. Faz com que muitas pessoas sejam incapazes de refletir sobre a letra do que está ouvindo, apenas repetem mecanicamente os refrãos. O indivíduo passa a imitar a voz e a expressão dos artistas, inclusive na música. O prazer do momento e da fachada de variedade transforma-se em pretexto para desobrigar o ouvinte a pensar no todo. Muitas pessoas se convertem em simples compradores e consumidores passivos.

A nova etapa da consciência musical das massas se define pela negação e rejeição do prazer no próprio prazer. Assemelha-se tal fenômeno aos comportamentos que as pessoas soem manter face ao esporte ou a propaganda. A expressão 'prazer artístico' ou 'gosto artístico' assumiram um significado curioso e cômico (Adorno, 1991, p. 83).

9 Adorno (1986a) descreve em Nova York, a música estandardizada nos Estados Unidos (que seria o sertanejo universitário brasile iro). Neste texto o autor diz que o consumidor desta música, se esforça ativamente para ser passivo. Ele sabe que a música é padronizada e que os acordes se repetem para que seja aceito pelo consumidor, que se esforça para continuar consumindo. Como se não tivesse outra possibilidade, acaba se conformando. Esta pesquisa foi fundamental para Adorno (1985) conceber a dialética do esclarecimento, e categorizar o consumidor da música popular. 
A música de consumo contribui para sujeitar a Arte aos processos de compra e venda destinando-se a um consumo não produtivo e qualificando-se, portando, sobretudo por seu valor de troca. Como mercadoria, pode ser consumida não somente por um público de elite, mas pelas grandes massas da população urbana.

Atualmente, com o advento da indústria do consumo, os bens culturais se estendem à toda sociedade com o rádio, todo o tipo de música chega até as pessoas, mas não significa que estas músicas contribuam para a formação das mesmas. Com isso as grandes empresas comerciais e industriais lucrariam muito com um rendoso mercado nas demandas culturais dessa população por meios de veiculação sonora como o rádio, Cd's, pen drive, celular, cinema e televisão. E não demorou muito para que as grandes empresas fonográficas monopolizassem a produção e a distribuição de tal mercadoria.

Adorno (1991, p. 84), discutindo sobre essas questões, escreve:

A música ligeira em relação à música clássica, tem como fundamento precisamente essa passividade das massas. Estas colocam o consumo da música ligeira como uma necessidade psicológica. É como se o ritmo do trabalho continuasse nos momentos de distração.

No dia a dia é comum observar que as pessoas em geral apreciam a música ligeira, e poucos conhecem a música clássica. Se a música estiver nas paradas de sucesso é o suficiente para que todos aceitem e aprovem como uma música popular (feita especialmente para as massas). O que é pior: este tipo de arte é consumida como uma mercadoria, adquirida em qualquer mercado.

Diante dessas mercadorias de fácil acesso, os indivíduos acabam por consumir simplesmente pelo valor da mídia. Algumas pessoas transformam-se em consumidores acríticos, deixando-se levar totalmente pela mídia, sem o mínimo de questionamento em relação à letra da música que se está ouvindo. Os consumidores, destaca Adorno (1991, p. 93), concordam com os critérios ditados pelos produtores e não percebem que este tipo de música tem baixa qualidade artística.

As reações inconscientes do público, dos ouvintes, são ofuscadas com tal perfeição, a apreciação consciente dos ouvintes é teleguiado com tal exclusividade pelos critérios fetichistas dominantes, que toda e qualquer resposta concorda a priore com a superfície mais banal deste cultivo musical atacado pela teoria cuja validade precisamente se quer 'verificar'.

O ouvinte acaba sendo um dependente da máquina dirigente da propaganda. Sua audição em relação à música regride cada vez mais. Com isso as pessoas tendem a demonstrar um comportamento conformista. As músicas de sucesso têm efeitos psicológicos sobre os ouvintes, que são influenciados constantemente pela mídia.

Adorno (1991) ressalta que, os meios de comunicação de massa, levam os ouvintes à regressão. Estes permanecem num estado infantil, porque ao invés de evoluir e refletir sobre o que estão ouvindo, tendem a regredir e a se acomodar, cada vez mais, em relação às músicas que são lançadas no mercado. Com isso os indivíduos perdem com a suposta liberdade de escolha. Isto porque se pode no máximo trocar de estação de rádio, pois as músicas que estão na parada de sucesso são as mesmas em todas as estações populares ${ }^{10}$. A possibilidade de se enxergar esta realidade é quase nula.

Adorno (1991, p. 97) escreve que:

[...] os ouvintes que somente tem a capacidade de ouvir, naquilo que lhes é proporcionado, o que se lhes exige e que registram o atrativo sensorial abstrato, ao invés de levarem os momentos de encantamento à síntese, constituem ouvidos da má qualidade [...] Os ouvintes, vítimas da regressão, comportam-se como crianças. Exigem sempre de novo, com malícia e pertinácia, o mesmo alimento que uma vez foi oferecido.

10 Atualmente existem rádios que fogem ao padrão da Indústria Cultural, mas poucos ouvintes tem interesse em ouvi-las. 
Infelizmente, a audição regressiva está presente em nossa sociedade, fruto desta realidade musical que contribui para formatar a audição do homem atual, impedindo novas possibilidades e questionamentos sobre este tipo de música do consumo. Adorno (1991, p. 182) é totalmente contra essa dominação, pois ele entende que ela “[...] só presta para camuflar o processo de dominação cultural inerente a um tal tipo de produção. Música popular é um termo que, a nosso ver, deve ser reservado para referir às manifestações musicais das classes populares".

Nos tempos atuais, a Indústria Cultural, enquanto produtora de música do consumo, não se importa em preservar a cultura brasileira, pois o que importa é o consumo. Evita-se, assim, toda e qualquer exigência de participação interpretativa por parte do ouvinte, pois segundo Adorno (1991) e uma sociedade administrada o consumo de música tende a processar-se em tempo integral, como se qualquer instante representasse tempo perdido. Neste sentido, a música do consumo, contribuir para massificar os indivíduos, que tem horror ao silêncio e buscam preencher o vazio do dia com os produtos da Indústria Cultural.

Embora a audição regressiva não constitua sintoma de progresso na consciência da liberdade é possível que, inesperadamente, a situação se modifique. Para tanto, é necessário que a arte abandone a rotina do sempre igual. A semiformação ('Halbbildung'), auxiliada muito de perto por um determinado tipo de linguagem, acaba por condicionar o homem, no sentido de fazer com que ele aceite e reproduza a ordem social que está estabelecida. Ela reforça atitudes e comportamentos que estão de acordo com a estrutura de poder totalitário, que domina sem mostrar a face. Palangana (1998, p. 160), afirma que “[...] os homens educados por meias verdades, são impedidos de compreender a existência real".

Na percepção de Adorno (1970) a arte só conseguiria recuperar a resistência em uma sociedade livre e se não estiver a serviço do poder. Neste contexto a arte estaria em estado de paralisia. O método crítico-dialético, que Adorno (1970) aplica à obra de arte, denuncia essa estrutura da sociedade pós-industrial, permitindo apreender o fenômeno artístico sob o aspecto do devir. Bertran (1019) escreve que a obra de arte possibilita o entendimento de contextos sociais, ficando visível a possibilidade de uma práxis distinta. A arte não possibilita uma mudança concreta na sociedade, mas sim na maneira do indivíduo entender a realidade concreta em que está inserido, possibilitando a prática crítica.

A música reconhece o direito que a sociedade ainda possui, pois somente a obra de arte transformada, converte-se em objeto do pensamento e participa dele. Desta forma, a obra de arte com sentido estético é algo mais que a aparência e ao mesmo tempo não mais do que esta, "[...] a contraposição imediata de 'coisa' e reflexão espiritual se torna absoluta e confere assim ao produto do sujeito a dignidade do natural" (Adorno, 2011, p. 112). Ou seja, a obra de arte, e nela a música, possibilita que o indivíduo eleve os seus sentimentos, desenvolva a estética, contribuindo para a elevação do pensamento a patamares superiores.

Mas diante do exposto percebe-se que o fator de maior peso no desenvolvimento do indivíduo - as relações socioculturais -, na atual conjuntura, sinalizam no sentido contrário ao desenvolvimento intelectual e à formação do pensamento analítico. Esta é uma tarefa da educação, onde os professores precisam primeiro, compreender e, depois, manter-se muito atentos ao caráter da Indústria Cultural. Para tanto, é necessário que o educador se aproprie de um referencial teórico que possibilite refletir sobre os mecanismos de manipulação dos quais se vale a cultura administrada e transmitida pela música, para que assim realizem um trabalho em sala de aula que possibilite o contraponto e a argumentação sobre esta realidade.

Adorno (1986b) destaca que a contradição entre a formação cultural e a sociedade de consumo acaba por proporcionar aos indivíduos a semicultura ${ }^{11}$, ou seja a semiformação cultural. Os homens deveriam ter uma educação que lhes

\footnotetext{
11 “Adorno mostra que, com a universalização do mercado da indústria cultural, a contradição entre a formação cultural e a sociedade de consumo não apresenta como resultado a não-cultura, o não-saber e sim a semicultura. No não-saber há uma predisposição do homem para a busca do saber. No semisaber a pessoa se julga sabedora e se fecha às possibilidades da sabedoria. A não-cultura, como mera ingenuidade e simples ignorância, permitia uma relação imediata com os objetos e, em virtude do potencial de ceticismo, engenho e qualidades que se desenvolvem naqueles que não são inteiramente" (Pucci, 1997, p. 164).
} 
possibilitassem refletir, analisar, criticar, enfim, que observassem e refletissem sobre sua vida na sociedade em que estão inseridos.

Adorno (1970), explica ainda que a música deve apresentar o movimento dialético empreendido no momento de sua autonomia. Mas, neste instante ocorre uma contradição: ver sua própria expressão isolada da coletividade. A autonomia a obra de arte deve surgir de uma função social. A obra autônoma e autêntica é capaz de transcender tanto o sistema social como a si mesma. Capacidade de libertar-se de sua existência e, ao mesmo tempo, denunciar a falsa aparência da sociedade. Nessa acepção, "[...] a revolta humana é tão mais violenta à medida que vê a própria música sucumbir à espoliação afetiva empreendida pela técnica" (Arzua, 2001, p. 177).

\section{Conclusão}

Dos estudos realizados, depreende-se que a arte e a música na sociedade Industrial, foi sendo padronizada, e as experiências formativas que a arte possibilitava até então, foram quase extintas. $\mathrm{O}$ gosto musical foi sendo moldado para determinados ritmos e os acordes se tornaram mecânicos, moldando a audição ao sempre igual, repetitivo e padronizado. Este contexto reflete-se no pensamento do homem, que está cada vez mais coisificado.

A Arte - e nela a música - possibilita a reflexão e a concretização dos sentimentos humanos que, muitas vezes, são passíveis de simbolização conceitual, sendo uma forma de despertar no indivíduo outras maneiras de pensar, de ver e ouvir, impostas pela sociedade de consumo. Mesmo que a sociedade atual não favoreça o desenvolvimento do pensamento do indivíduo a patamares superiores, pois objetivam a produção artística em mercadorias, ainda existe a possibilidade de fuga, da contradição, pois a música pode apresentar o movimento dialético capaz de transcender tanto o sistema social como a si mesma, oportunizando ao homem libertar-se de sua existência e, ao mesmo tempo, denunciar a falsa aparência da sociedade.

Conclui-se que a produção artística na sociedade atual não favorece o desenvolvimento do pensamento do indivíduo a patamares superiores, pois objetivam a produção da Arte em escala industrial, em mercadorias - inclusive a produção musical. Mas a arte filosoficamente possui essa potencialidade negativa e o indivíduo pode experimentar a música como algo em si, que possibilite não apenas um momento de lazer, mas sim que pode possibilitar a experiência estética como um ato formativo. Os gestos da arte são respostas objetivas das necessidades sociais, e esses gestos pressupõem sua própria dialética que, por sua vez, pode contribuir para desvelar a realidade, oferecendo elementos para o enfrentamento desta situação. Para tanto é necessário que a educação contribua para formar nos alunos, reflexões sobre as relações que permeiam o dia a dia não só das crianças, mas de todos os homens.

Este estudo não se esgota aqui, pois percebe-se que a arte ou o seu ensino possuem um potencial estético, mas quando são aplicados nas escolas, ficam desvinculados, ou fragmentados, pois os professores não conseguem compreender seu real potencial formador e emancipador. Essa maneira de definir a arte a afasta de seu real objetivo quando ensinada nas escolas de educação fundamental, pois ela deixa de ser promotora de sensibilidade estética, perde o seu objetivo de formação e de emancipação humana. Diante do exposto os autores buscarão discorrer nas próximas pesquisas, sobre o conceito de estética, bem como sobre a experiência estética que a arte proporciona aos indivíduos, relacionando-o ao ensino de arte e da música nas escolas brasileiras.

\section{Referências}

Adorno, T. W. (1970) Teoria Estética. Frankfourt: Edições 70.

Adorno, T. W. Sociologia. (1986a) In: Cohn, G. (Org.). Coleção Grandes Cientistas Sociais. Ática, p. 81-98.

Adorno, T. W. Sobre Música Popular. (1986b) In: Cohn, G. (Org.). Coleção Grandes Cientistas Sociais Ática, 115-146. 
Research, Society and Development, v. 10, n. 4, e36710414123, 2021

(CC BY 4.0) | ISSN 2525-3409 | DOI: http://dx.doi.org/10.33448/rsd-v10i4.14123

Adorno, T. W. O Fetichismo na Música e a Regressão da Audição. (1991) In: Horkheimer, M.; Adorno, T. W. Textos Escolhidos. Nova Cultural, $79-185$ (Os Pensadores).

Adorno, T. W. (2007) Filosofia da Nova Música. Perspectiva.

Adorno, T. W.(2009) Dialética Negativa. Jorge Zahar.

Adorno, T. W. (2011) Introdução à Sociologia da Música. Unesp.

Adorno, T. W \&; Horkheimer, M. (1985) Dialética do Esclarecimento: Fragmentos Filosóficos. Jorge Zahar.

Arzua, G. (2001) Reificação e Autonomia: A Dupla Face da Razão na Estética Musical de Adorno. In: Oliveira, N. R, Zuin, A. A. S, Pucci, B. (Org.) Teoria Crítica, Estética e Educação. Campinas, SP: Autores Associados. p. 175-184.

Bertram, G. W. (2019). Teoria estética de Adorno e a questão da eficácia social da arte. Dissonância: Revista de Teoria Crítica, 3(2), Dossiê Theodor W. Adorno, $2^{\circ}$ semestre de 2019, pp. 85-111.

Colarusso, O. Carmine Burana. Os Segredos de um dos Hits da Música Clássica. Gazeta do Povo. http://www.gazeta dopovo.com.br/blogs/falando-demusica/carmina-burana-os-segredos-de-um-dos-hit s-da-musi ca-classica/.

Duarte, R. (2001) Mundo "Globalizado" e Estetização da Vida. In: Oliveira, N. R.; Zuin, A. A. S.\& Pucci, B. (Org.). Teoria Crítica, Estética e Educação. Autores Associados. p. 27-42.

Fabiano, L. H. (2001) Bufonices Culturais e Degradação Ética: Adorno na Contramão da Alegria. In: Oliveira, N. R., Zuin, A. A. S., Pucci, B. (Org.).Teoria Crítica, Estética e Educação. Autores Associados. 135-146.

Fianco, F. (2020) Arte e sociedade em "teoria estética" de Theodor Adorno. Art Research Journal, 7(1).

Hartmann, H. R. Adorno. (2001) Arte e Utopia. Entre o Pessimismo Político e o Otimismo Estético. In: Oliveira, N. R., Zuin, A. A. S., Pucci, B. (Org.). Teoria Crítica, Estética e Educação. Autores Associados. p.75-92.

Kiihl,R. N. (2019) Experiência Estética e Educação: a contribuição histórica de Theodor Wiesegrund Adorno, Vitória: Universidade Federal Espírito Santo, dissertação Mestrado, 99 f.

Loureiro, E. C. V. (2016) Schoenberg/Boulez: Ideia/Sistema. Per musi, Belo Horizonte, 33, 25-58.

Lüdke, M. (1986) Pesquisa em educação: abordagens qualitativas. EPU. P. 35-44.

Marcuse, H. (1967) A Ideologia da Sociedade Industrial. Zahar.

Marcuse, H. (1977) A Dimensão Estética. Martins Fontes.

Moreira, P. L.\& Silva, R. T. M. (2018) Teoria Crítica e Indústria Cultural: Apontamentos sobre Educação e Cinema. Goiânia: Novas Edições Acadêmicas.

Nogueira, M. A. (2001) Música, Consumo e Escola: Reflexões Possíveis e Necessárias. In: Oliveira, N. R., Zuin, A. A. S., Pucci, B. (Org.). Teoria Crítica, Estética e Educação. Autores Associados. p. 185- 195.

Palangana, I. C. (1998) Individualidade: Afirmação e Negação na Sociedade Capitalista. Plexus/EDUC.

Penna, M. (2012) Música(s) e Seu Ensino. Sulinas.

Pucci, B. (1997) Filosofia Negativa e Educação: Adorno. Filosofia, Sociedade e Educação, Marília, 1(1), 163-192.

Ribeiro, E. C. S. R., Spbral, K. M., \& Jataí, R. P. (2016) Omnilateralidade, Politecnia, escola unitária e educação tecnológica: uma análise marxista. In: Jornada Internacional De Estudos E Pesquisas Em Antonio Gramsci, 1;, Práxis, Formação Humana e a Luta por uma Nova Hegemonia. 7., 2016. Fortaleza. Anais... Fortaleza: Universidade Federal do Ceará; JOINGG. p. 1-11.

Santana, L. (2017) Cantor brasileiro. e-biografia. https://www.ebiografia.c om/luan_santana/.

Vilela. A, R. A. T. A (2012 Pesquisa Empírica da Sala de Aula na Perspectiva da Teoria Crítica: Aportes Metodológicos da Hermenêutica Objetiva de Ulrich Oevermann. In: Pucci, B.; Costa, B. C. G. (Org.). Teoria Crítica e Crises: Reflexões sobre Cultura, Estética e Educação. Autores Associados p. $157-180$.

Triviños, A. N. S. (1987) Introdução à pesquisa em ciências sociais: a pesquisa qualitativa em educação. Atlas. 